\title{
Are critical size bone notch defects possible in the rabbit mandible?
}

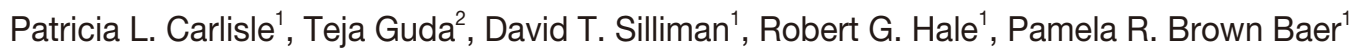 \\ ${ }^{\prime}$ Department of Craniomaxillofacial Regenerative Medicine, Dental and Trauma Research Detachment, Fort Sam Houston, TX, \\ ${ }^{2}$ Department of Biomedical Engineering, University of Texas at San Antonio, San Antonio, TX, USA
}

\begin{abstract}
J Korean Assoc Oral Maxillofac Surg 2019;45:97-107)
Objectives: Small animal maxillofacial models, such as non-segmental critical size defects (CSDs) in the rabbit mandible, need to be standardized for use as preclinical models of bone regeneration to mimic clinical conditions such as maxillofacial trauma. The objective of this study is the establishment of a mechanically competent CSD model in the rabbit mandible to allow standardized evaluation of bone regeneration therapies.

Materials and Methods: Three sizes of bony defect were generated in the mandibular body of rabbit hemi-mandibles: $12 \mathrm{~mm} \times 5 \mathrm{~mm}, 12 \mathrm{~mm} \times 8$ $\mathrm{mm}$, and $15 \mathrm{~mm} \times 10 \mathrm{~mm}$. The hemi-mandibles were tested to failure in 3-point flexure. The $12 \mathrm{~mm} \times 5 \mathrm{~mm}$ defect was then chosen for the defect size created in the mandibles of 26 rabbits with or without cautery of the defect margins and bone regeneration was assessed after 6 and 12 weeks. Regenerated bone density and volume were evaluated using radiography, micro-computed tomography, and histology.

Results: Flexural strength of the $12 \mathrm{~mm} \times 5 \mathrm{~mm}$ defect was similar to its contralateral; whereas the $12 \mathrm{~mm} \times 8 \mathrm{~mm}$ and $15 \mathrm{~mm} \times 10 \mathrm{~mm}$ groups carried significantly less load than their respective contralaterals $(P<0.05)$. This demonstrated that the $12 \mathrm{~mm} \times 5 \mathrm{~mm}$ defect did not significantly compromise mandibular mechanical integrity. Significantly less $(P<0.05)$ bone was regenerated at 6 weeks in cauterized defect margins compared to controls without cautery. After 12 weeks, the bone volume of the group with cautery increased to that of the control without cautery after 6 weeks.

Conclusion: An empty defect size of $12 \mathrm{~mm} \times 5 \mathrm{~mm}$ in the rabbit mandibular model maintains sufficient mechanical stability to not require additional stabilization. However, this defect size allows for bone regeneration across the defect. Cautery of the defect only delays regeneration by 6 weeks suggesting that the performance of bone graft materials in mandibular defects of this size should be considered with caution.
\end{abstract}

Key words: Bone regeneration, Rabbit, Mandible, Micro-computed tomography, Cautery

[paper submitted 2018. 5. 18 / revised 2018. 8. 2, / accepted 2018. 8. 3]

\section{Introduction}

Maxillofacial injuries from trauma cause large deficits in bone, specifically in the mandible which require surgical restoration. Automobile accidents in the civilian population, gunshot wounds in armed conflict, and various battlefield injuries cause significant trauma to the maxillofacial skeleton and recent studies have shown that the mandible is most affected ${ }^{1,2}$. The treatment required to return structure and function to these injuries is often achieved at great cost. In order

\footnotetext{
Teja Guda

Department of Biomedical Engineering, University of Texas at San Antonio, One UTSA Circle, AET 1.356, San Antonio, TX 78249, USA

TEL: +1-210-458-8529 FAX: +1-210-458-7007

E-mail:teja.guda@utsa.edu

ORCID: https://orcid.org/0000-0002-3218-2916

(c) This is an open-access article distributed under the terms of the Creative Commons Attribution Non-Commercial License (http://creativecommons.org/ licenses/by-nc/4.0/), which permits unrestricted non-commercial use, distribution, and reproduction in any medium, provided the original work is properly cited. Copyright (C) 2019 The Korean Association of Oral and Maxillofacial Surgeons. All rights reserved.
}

to reduce the restorative burden, many regenerative therapies are currently in development to promote bone regeneration and engraftment. Synthetic bone graft substitutes comprise a rapidly expanding field that aims to address the drawbacks of autologous bone grafting to repair bony non-unions.

Non-unions are translationally assessed by their ability to regenerate critical-sized bone defects in animal models; that are otherwise not expected to heal significantly over the life of the animal. A critical size defect (CSD) in bone is defined as a defect of a size that heals predominantly with fibrous tissue, not bone, during the life span of the animal ${ }^{3}$. The calvarial CSD model in rats ${ }^{4,5}$ and rabbits ${ }^{6,7}$ is commonly used to gauge therapy safety before evaluating the efficacy of therapy in larger animal models $\left(\right.$ canine $^{8}$ or porcine ${ }^{9,10}$ ). However, the limitations associated with cost and use of companion animals in the large animal studies and the insufficiency of cranial models to account for mandible specific requirements limits the effective assessment of novel therapeutics. It is important to develop an appropriate animal model that can re- 
generate bone in the maxillofacial skeleton to account for the unique challenges presented by the anatomy of the mandible. The difficulties of regenerating bone in mandibular defects include soft tissue in growth ${ }^{11}$, insufficient blood supply ${ }^{12}$, and the forces of flexation and mastication ${ }^{13}$. There is thus a clear need for well-characterized small animal mandible specific bone regeneration models to effectively assess regenerative therapeutics ${ }^{14}$.

While mandible segmental continuity defect models have been evaluated in rabbits, mechanical instability of the mandibular complex after defect creation requires additional fixturing for stabilization. This fixturing, including miniplates ${ }^{15}$ and bicortical screws ${ }^{16}$, leads to a complex biomechanical model, which detracts from the simple screening models that would allow for quick transition into large animal models. Additionally, these models have often involved defect creation in the anterior third of the mandible in locations that have less physiological relevance in humans ${ }^{16}$.

Partial thickness bone defect models of the rabbit mandible are biomechanically stable but are not stringent enough and lack direct physiological relevance. In these models, the regeneration of bone is induced in areas that are typically populated with bone marrow ${ }^{17}$. The defect site is completely protected from microstrains due to the retention of the lingual cortex, potentially affecting the regenerative process. Partial thickness defects have also resulted in significant bone regeneration compared to full thickness defects ${ }^{18}$. In terms of evaluating therapies for implant fixation and treatment of edentulous patients, the alveolar full thickness model is potentially the most physiologically relevant ${ }^{19}$; however, current models may not be relevant in evaluating tooth-extraction type or periodontal cell driven regeneration scenarios ${ }^{18}$. More recent models involve the use of trephines to create full thickness $^{20,21}$ or partial thickness ${ }^{22}$ windows in the mandible that are then used to evaluate bone regeneration materials. While these sometimes lead to alveolar ridge collapse and continue to need metallic plate fixators for stabilization and to avoid iatrogenic fractures ${ }^{23}$, they are also similar to calvarial models in that they heal by the radial in-growth of bone. This is not typical of bone defects in the mandible of traumatic injuries or cancer resections which are usually 3 wall defects.

Thus the mandibular notch defect model in rabbits offers a potential model for simple yet effective therapy safety evaluation for bone regeneration if a CSD is appropriately set up and characterized. However, multiple sizes of defects have been created in this model ranging (from 90 to $450 \mathrm{~mm}^{3}$ ) $24-26$. Additionally, these models are sometimes created bilaterally and sometimes need additional stabilization with stainless steel wires to either keep the scaffold therapy in place or to ensure mechanical integrity ${ }^{27,28}$. In many cases, significant instances of spontaneous bone regeneration have been observed $^{25,26}$, or an untreated empty defect was not a part of the study design ${ }^{28-30}$, raising questions regarding whether this model can serve as an appropriate CSD. The lack of standardization in the rabbit mandible notch model detracts from the extrapolation of results observed in previous studies for clinical translation or comparison to results in similar studies in the field for alternate therapeutics. To address these concerns, the objective of the current study was to identify the bone defect size in the inferior mandibular body which maintains biomechanical competence and to then establish whether a 3 wall notch defect functions as a CSD when the bone edges are cauterized.

\section{Materials and Methods}

\section{Experimental design}

Mandibles from skeletally mature New Zealand White rabbits in an unconnected study were harvested for mechanical testing. Notch type defects of various dimensions were made in the body of the mandible and the flexural properties of the hemi-mandibles were tested in a 3-point bending mode. The defect size which did not significantly compromise mechanical strength and modulus of the hemi-mandible was chosen for further in vivo evaluation. Bone regeneration in untreated mandibular notch defects either with or without cautery of the bone margins was evaluated for a period of 6 or 12 weeks using micro-computed tomography (micro-CT) and histomorphometry to determine if the model was a CSD.

\section{Mechanical testing}

Mandibles from 23 New Zealand White rabbits were harvested, cleaned of connective tissues and split along the symphysis to create two hemi-mandibles. Three sizes of bony defects were generated in the mandibular body: $12 \mathrm{~mm} \times 5$ $\mathrm{mm}, 12 \mathrm{~mm} \times 8 \mathrm{~mm}$, and $15 \mathrm{~mm} \times 10 \mathrm{~mm}$ to match defect sizes previously reported to be $\operatorname{CSDs}^{24,25,31,32}$. The contralateral hemi-mandibles with no defects were used as controls for flexural testing. All hemi-mandibles were tested to failure in a 3-point flexure mode at a constant strain rate of $1 \mathrm{~mm} /$ min while supported across a $30 \mathrm{~mm}$ span on a universal testing machine (Lloyd LRX; Lloyd Instruments, West Sussex, 
UK). The lingual side of the mandible was facing down and a 5-mm thick foam rubber was placed between each sample and the loading supports to evenly distribute the load using methods previously reported for rabbit mandible flexural testing $^{33,34}$. The flexural modulus and strength were calculated from the test data collected ( $\mathrm{n}=8$ samples/group, $\mathrm{n}=7$ samples for the $15 \mathrm{~mm} \times 10 \mathrm{~mm}$ defect size).

\section{Animal model}

The $12 \mathrm{~mm} \times 5 \mathrm{~mm}$ defect size was chosen for the in vivo study of bone regenerative potential in the rabbit mandible. Twenty-six female New Zealand White rabbits, at least 5 months of age and ranging in weight between 4-5 kg underwent unilateral surgery to evaluate bone regenerative potential. These animals were divided into 3 groups: 6 animals underwent defect creation with no cautery of the defect edges and were evaluated at 6 weeks; 10 animals underwent defect creation with cautery of the bone defect margin and were evaluated after 6 and 12 weeks respectively. The animals were given a pre-anesthetization analgesic $(0.025-0.05 \mathrm{mg} / \mathrm{kg}$ buprenorphine hydrochloride subcutaneously) and anesthetized using Telazol $(12.5 \mathrm{mg} / \mathrm{kg}$ intramuscularly) for induction and isoflurane (1.5\%-4\%) in oxygen for maintenance of general anesthesia. An incision was created along the inferior border of the rabbit mandible and the periosteum was elevated. Using a bone saw, cooled with copious sterile saline, a measured osseous defect was created along the inferior border of the mandible, immediately anterior to the antegonial notch, measuring $5 \mathrm{~mm}$ in depth $\times 12 \mathrm{~mm}$ in length $\times$ full thickness, resulting in a 3-wall defect.(Fig. 1) To guide the surgical defect formation and histological analysis, gutta-percha was placed into small holes created in the cortical bone 10 $\mathrm{mm}$ from the inferior border of the mandible at 3 points $(0,6$, and $12 \mathrm{~mm}$ ). This defect was positioned anatomically anterior to the masseter muscle, posterior to the digastric muscle insertion (on the medial mandible surface) and inferior to the mental foramen. In the model with cautery, the superior bone margin of the defect was cauterized (Loop tip surgical cautery; Ahco Dealers, Nashville, TN, USA). The soft tissues were then approximated and closed in layers with resorbable 3-0 Vicryl sutures. At the conclusion of the surgery, a $25 \mu \mathrm{g} /$ hr transdermal fentanyl patch was affixed to the dorsum in the interscapular region and maintained in place for 3 days for continued analgesia. After 6 weeks in the non-cautery group or 6 and 12 weeks in the groups with cautery, animals were euthanized via intravenously administered Fatal-Plus (1 mL/4.5 kg; Vortech Pharmaceuticals, Dearborn, MI, USA) and both hemi-mandibles were harvested and stored in neutral buffered formalin for further evaluation and analysis.

\section{Radiography and micro-CT evaluation}

Radiographs were acquired using a Faxitron MX20 X-ray Digital System (Faxitron X-ray, Wheeling, IL, USA) for each mandible after extraction. The images were captured at 25 $\mathrm{kV}$ in a 15 seconds exposure time and imported into Faxitron DR software (ver. 3.2.2; Faxitron Bioptics LLC, Tuscon, AZ, USA). Micro-CT analysis was performed using a Skyscan 1072 scanner (Bruker, Kontich, Belgium) at a resolution of $17.0 \mu \mathrm{m}$ pixel on samples hydrated with formalin. The images were reconstructed using NRecon software (BrukerMicroCT) to generate grayscale images ranging from 0 to 255. DataViewer was used to re-align the hemi-mandible images so that the primary axes were the principal physiological axes of the mandible. Global thresholding was performed on
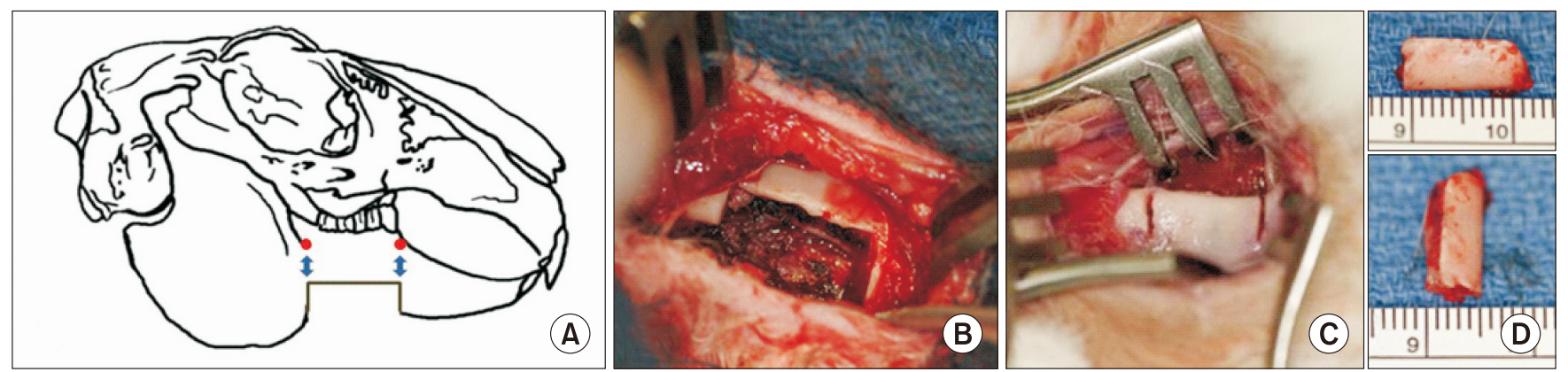

Fig. 1. Bone defect creation in the mandibular body. A, B. The $12 \mathrm{~mm} \times 5 \mathrm{~mm}$ defect was created in the region just anterior to the antegonial notch and gutta-percha markers were included $5 \mathrm{~mm}$ above the initial defect corners as radiographic markers. C, D. The bone defect is created by making two vertical cuts $12 \mathrm{~mm}$ apart and $5 \mathrm{~mm}$ deep using an oscillating saw to remove the inferior cortex and marrow of the mandibular body.

Patricia L. Carlisle et al: Are critical size bone notch defects possible in the rabbit mandible? J Korean Assoc Oral Maxillofac Surg 2019 
the samples across all the groups in the study using the Otsu algorithm to identify mineralized tissue. The defect created was then located to define the region of interest $12 \mathrm{~mm}$ in length along the full thickness of the mandible and the border of this region of interest was determined using the borders of the contralateral hemi-mandible. The three-dimensional (3D) mineralized volume, bone mineral density, and mineralized area distribution analysis along the $12 \mathrm{~mm}$ defect length were carried out on CT images using CT analyzer. These analyses were carried out for all the experimental groups in the study as well as their respective contralateral hemi-mandibles.

\section{Histological evaluation}

The excised mandibles were prepared for histology as previously described. Briefly, samples were dehydrated in ascending grades of ethanol, followed by xylene at $4^{\circ} \mathrm{C}$ and then embedded in poly(methyl methacrylate). The specimens were then cut and ground to $30 \mu \mathrm{m}$ thick sections using a diamond saw and MicroGrinder (Exakt Technologies, Oklahoma City, OK, USA). This was performed for 4 samples in the 6-week group without cautery, 6 samples in the 6-week group with cautery, and 7 samples in the 12-week group with cautery. The sections were mounted on slides and stained with Sanderson's Rapid Bone Stain and counterstained with van Gieson's picrofuchsin to stain soft tissue blue and bone pink/red. Cellular tissue debris was stained black.

Histology slide images of $2.0 \times$ magnification were acquired on an Olympus SZX16 Research High-Class Stereo Microscope (Olympus, Center Valley, PA, USA) with an Olympus DP71 Microscope Digital Camera and compiled using Photoshop (v7.0.1; Adobe Systems, San Jose, CA, USA). High magnification images $(40 \times$ and $100 \times)$ were acquired on a Nikon Eclipse 55i Research Microscope with a DS-f11 Digital Camera (Nikon Instruments, Melville, NY, USA). The entire defect area was selected by manually tracing the outer boundary and the number of pixels was quantified. Mineralized tissue was selected within the defined defect area by a color threshold of the pink/red stain and the number of bone pixels was measured. The percentage of the mineralized tissue was calculated as the ratio of the mineralized tissue to the defect area. The presence of mineralization in the bone canals and the presence of cellular/tissue debris at the defect edges was scored and reported as a percentage of the number of samples in the group.

\section{Statistical analysis}

All data are represented as the mean \pm standard error of the mean. Significance in flexural mechanical testing and microCT bone volume measures reported was determined using a paired t-test between the experimental and contralateral groups. Significance in the bone area fill from the histomorphometric analysis was determined using one-way ANOVA with Tukey's test for post hoc analysis. A significant level of differences between observed proportions of cellular debris and canal mineralization was determined using the z-test and applying the Yates correction for sample size. The level of significance was set at $P<0.05$ for all statistical measures reported. All statistical analysis was performed on Sigmaplot software (ver. 14.0; Systat Software, San Jose, CA, USA).

\section{Results}

\section{Mechanical testing}

In terms of flexural stress to failure, the $12 \mathrm{~mm} \times 5 \mathrm{~mm}$ defects $(163 \pm 9 \mathrm{MPa})$ were not significantly different from their contralaterals $(191 \pm 10 \mathrm{MPa})$; while the $12 \mathrm{~mm} \times 8 \mathrm{~mm}$ $(169 \pm 10 \mathrm{MPa}$ vs $253 \pm 32 \mathrm{MPa})$ and $15 \mathrm{~mm} \times 10 \mathrm{~mm}(122 \pm 9$ MPa vs $215 \pm 15 \mathrm{MPa}$ ) groups carried significantly less load than their respective contralateral controls $(P<0.05)$. The flexural stiffness of the hemi-mandibles had similar trends. (Table 1) No differences were observed between the control and the $12 \mathrm{~mm} \times 5 \mathrm{~mm}$ defect size while both groups of hemimandibles with $12 \mathrm{~mm} \times 8 \mathrm{~mm}$ and $15 \mathrm{~mm} \times 10 \mathrm{~mm}$ defects

Table 1. Mechanical flexural properties of hemi-mandibles with different sized defects

\begin{tabular}{cccc}
\hline \multirow{2}{*}{ Size } & \multicolumn{2}{c}{ Strength $(\mathrm{MPa})$} & \multicolumn{2}{c}{ Stiffness $(\mathrm{MPa})$} & Defect side \\
\cline { 2 - 4 } & Defect side & Contralateral & $41 \pm 3$ \\
\hline $12 \mathrm{~mm} \times 5 \mathrm{~mm}$ & $163 \pm 9$ & $191 \pm 10$ & $44 \pm 5^{*}$ \\
$12 \mathrm{~mm} \times 8 \mathrm{~mm}$ & $169 \pm 10^{*}$ & $253 \pm 32$ & $24 \pm 3^{*}$ \\
$15 \mathrm{~mm} \times 10 \mathrm{~mm}$ & $122 \pm 9^{*}$ & $215 \pm 15$ & $58 \pm 7$ \\
\hline
\end{tabular}

Flexural strength and flexural stiffness of hemi-mandibles with defects of different sizes at the inferior margin of the mandibular body compared to matched contralateral controls.

Asterisk indicates defect side has significantly reduced biomechanical properties compared to the contralateral, $* P<0.05$.

Patricia L. Carlisle et al: Are critical size bone notch defects possible in the rabbit mandible? J Korean Assoc Oral Maxillofac Surg 2019 


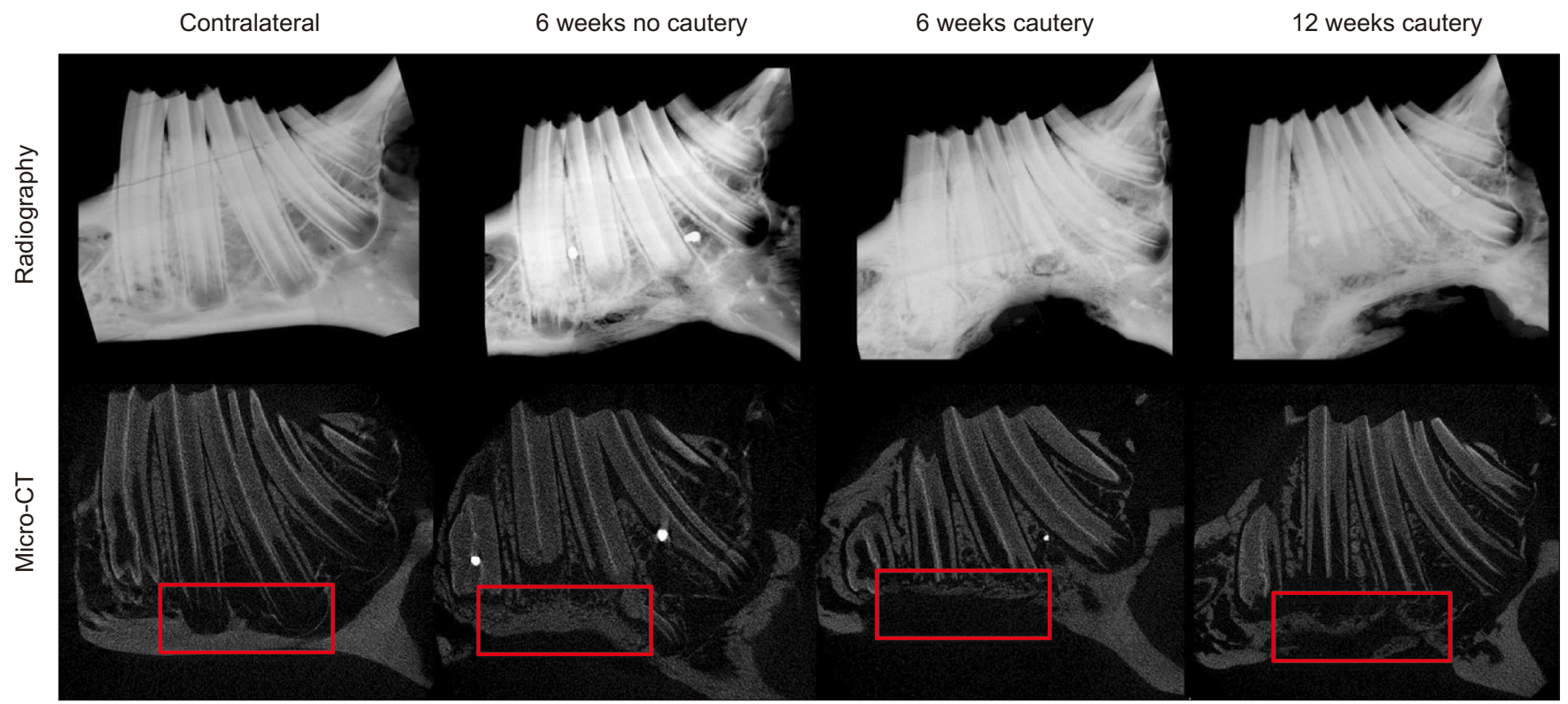

Fig. 2. Radiographic and micro-computed tomography (micro-CT) assessment of hemi-mandibles. Radiographs of the contralateral hemimandibles showing intact architecture and representative images from the three experimental groups showing regenerated bone after 6 or 12 weeks post defect creation. Micro-CT longitudinal sectional images of representative animals from each of the experimental groups showing bone regeneration within defect sites (boxed) compared to non-surgical control sites shown in the contralateral hemi-mandible (boxed).

Patricia L. Carlisle et al: Are critical size bone notch defects possible in the rabbit mandible? J Korean Assoc Oral Maxillofac Surg 2019

had significantly poorer flexural properties than their intact contralateral hemi-mandibles $(P<0.05)$. This study demonstrated that the $12 \mathrm{~mm} \times 5 \mathrm{~mm}$ defect did not significantly compromise the mechanical integrity of the mandible and this size of defect was chosen to further evaluate whether spontaneous regeneration of bone occurred in the mandible when defects of this size were created.

\section{Radiography and micro-CT evaluation}

Radiographic analysis revealed that opaque bridging of the defect site was present in the defect without cautery at 6 weeks, although the quality of the opacity was less than that in the cortex of the contralateral hemi-mandibles. Very limited opacity was observed in the defect site of the groups with cautery after 6 weeks, however, the opacity increased at the 12-week time point.(Fig. 2) Representative micro-CT cross sections of the groups indicating the defect site are also presented.(Fig. 2) The micro-CT data was used to quantify the bone volume in 3D. Without cautery at 6 weeks, no difference in bone volume within the defect was detected between the surgical mandible and its contralateral control.(Fig. $3)$ In terms of regenerated bone volume, significantly less bone was regenerated at 6 weeks with cautery $\left(70.5 \pm 9 \mathrm{~mm}^{3}\right)$ of the defect margins when compared to the group without

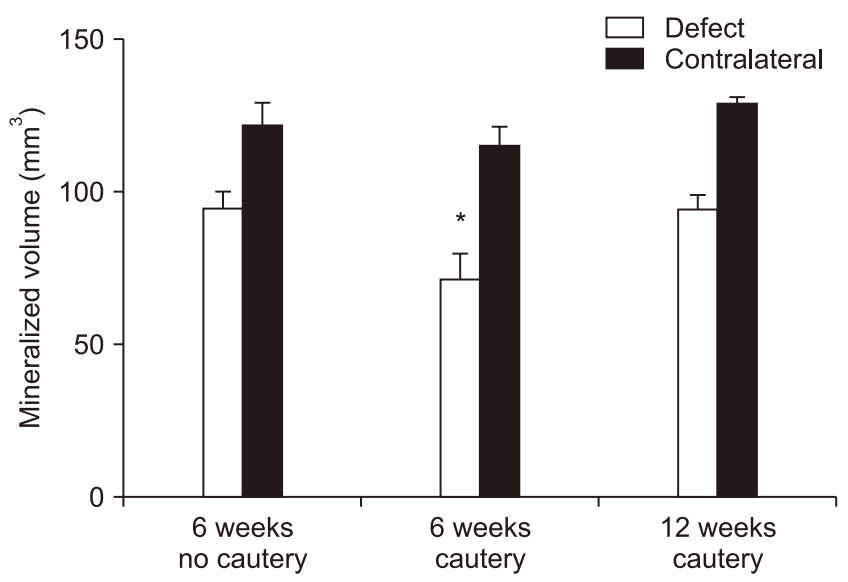

Fig. 3. Bone volume at defect site in micro-computed tomography (micro-CT) analysis. The bone volumes in the defect groups without cautery at 6 weeks and with cautery at 12 weeks were not significantly different from their contralateral controls, but the bone volume in the defect group with cautery was significantly lower compared to the contralateral hemi-mandible after 6 weeks $\left({ }^{\star} P<0.05\right)$.

Patricia L. Carlisle et al: Are critical size bone notch defects possible in the rabbit mandible? JKorean Assoc Oral Maxillofac Surg 2019

cautery $\left(93.6 \pm 6 \mathrm{~mm}^{3}\right)$ at 6 weeks. After 12 weeks, the group with cautery showed increased bone volume $\left(93.1 \pm 5 \mathrm{~mm}^{3}\right)$ equivalent to the 6 weeks group without cautery.(Fig. 3) For comparison, the contralateral hemi-mandibles had an average of $120.4 \pm 7 \mathrm{~mm}^{3}$ of bone and the total volume of the defect 
was $264.5 \pm 13 \mathrm{~mm}^{3}$. In terms of regenerated bone volume, the micro-CT analysis showed significantly less bone was regenerated at 6 weeks in the hemi-mandibles with cautery

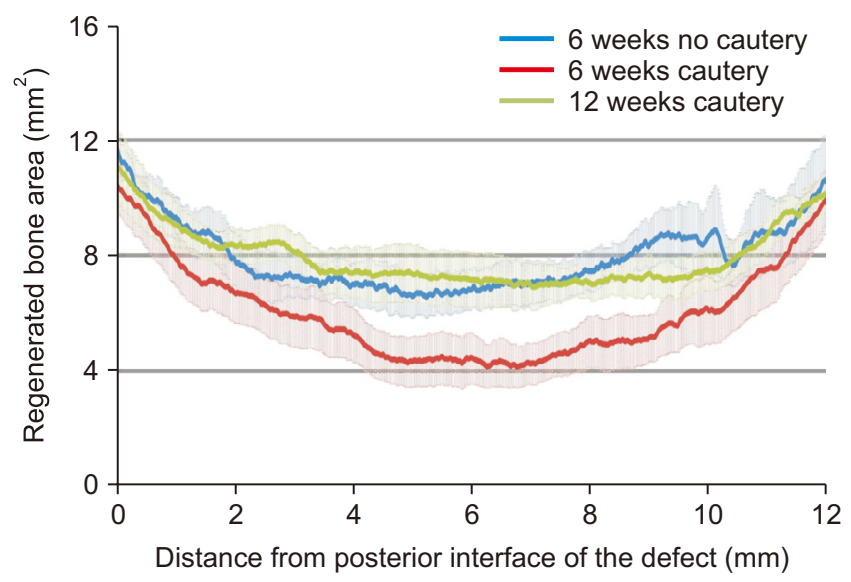

Fig. 4. Bone regeneration patterns within the defect in microcomputed tomography (micro-CT) analysis. The bone volume regenerated within each group was evaluated at every $17 \mu \mathrm{m}$ along the defect from the posterior to the anterior margin. This evaluation showed that while there was no difference in regeneration patterns between the defect with no cautery at 6 weeks (in blue) and the defects with cautery after 12 weeks (in green), significantly less bone was regenerated at every location in the defects with cautery after 6 weeks (in red) compared to the other two groups. Patricia L. Carlisle et al: Are critical size bone notch defects possible in the rabbit mandible? J Korean Assoc Oral Maxillofac Surg 2019 compared with their respective contralaterals $(P<0.05)$.(Fig. 3)

The regenerated bone mineral density within the defect space was $91.1 \% \pm 1 \%$ of the contralateral hemi-mandibles for the group without cautery after 6 weeks, and $88.3 \% \pm 2 \%$ of the contralateral hemi-mandibles for the group with cautery after 6 weeks, and $86.8 \% \pm 1 \%$ after 12 weeks, with no significant difference between groups. None of the experimental hemi-mandibles were found to be significantly different in terms of BMD from the contralateral hemi-mandibles either. The evaluation of the bone at every cross-section along the defect length indicated that not only did the group without cautery at 6 weeks and the group with cautery at 12 weeks regenerate a greater bone area than the group with cautery at 6 weeks, they did so at every location along the anterior-posterior axis of the defect.(Fig. 4) Additionally, it was clearly observed from the bone regeneration patterns at the defect site that bone in-growth occurred from each of the three walls of the defect.

\section{Histological evaluation}

Gross histological examination of the experimental groups indicated similar trends to those indicated in micro-CT analy-

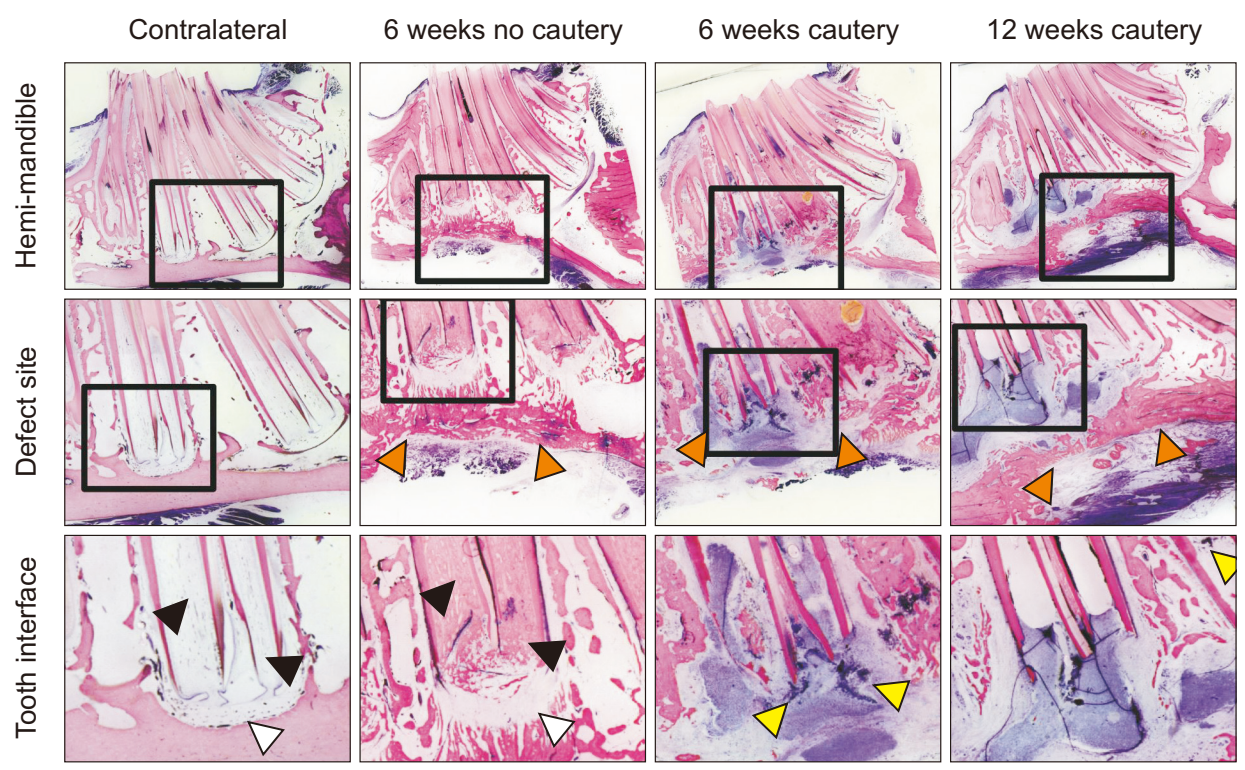

Fig. 5. Histological evaluation showing bone regeneration, intercanal ossification, and cellular debris. Histological sections were prepared along the longitudinal axis of the hemi-mandibles and stained with Sanderson's Rapid Bone stain and counterstained with van Geison's stain to label mineralized tissue pink and soft tissue blue $(\times 2)$. While a ridge of bone regenerated the cortex in the defects without cautery at 6 weeks and in the defects with cautery at 12 weeks, no such regeneration was seen in the defects with cautery after 6 weeks (orange arrows). At the defect margins, cellular debris was observed in the groups with cautery of the margins (yellow arrows). While the hemimandibles had clear tooth canals, the tooth canals in the defects without cautery had ossification after 6 weeks (black arrows), possibly due to a robust regenerative response from the periodontal tissues (white arrows).

Patricia L. Carlisle et al: Are critical size bone notch defects possible in the rabbit mandible? J Korean Assoc Oral Maxillofac Surg 2019 
Table 2. Histological analysis of the presence of cellular debris and bone tissue in teeth canals

\begin{tabular}{lccc}
\hline & $\begin{array}{c}6 \text { weeks } \\
\text { no cautery }\end{array}$ & $\begin{array}{c}6 \text { weeks } \\
\text { cautery }\end{array}$ & $\begin{array}{c}12 \text { weeks } \\
\text { cautery }\end{array}$ \\
\hline Cellular debris & 0 & 83.3 & 71.4 \\
Canal mineralization & 100 & 53.3 & 57.1 \\
\hline
\end{tabular}

Values are presented as $\%$.

The percentage of animals demonstrating either the presence of cellular debris at the defect margins or the growth of mineralized tissue within the root canals in each of the experimental groups is listed.

Patricia L. Carlisle et al: Are critical size bone notch defects possible in the rabbit mandible? J Korean Assoc Oral Maxillofac Surg 2019

sis. Bridge-like bone-fronts spanned the defect site margins in the 6-week group without cautery and the 12-week group with cautery, whereas limited bone growth was seen within the defect in the 6-week group with cautery. The histological sections also revealed localized inflammatory tissue debris present at the interface of the apex of teeth and the superior defect border in groups when cauterization was used, at both 6 and 12 weeks.(Fig. 5) No such cellular debris was seen in the non-cautery group. Also noted in the histology was the presence of bone growth into the root canals of the cut teeth.(Fig. 5) The proportion of animals within each group in which either cellular debris or canal mineralization was observed are listed in Table 2. While there was no statistical significance in the prevalence of inflammation or bone in the root canals, there was a strong trend $(P=0.054$ in the 6 -week no cautery vs 6 -week cautery) that cauterization resulted in the presence of increased cell debris and impacted the quality of healing. The histomorphometry data showed similar trends to that of the micro-CT, but no significant differences between surgical groups were found.(Fig. 6)

\section{Discussion}

This study investigated defects, previously claimed to be CSDs, in the rabbit mandible in terms of their effect on the biomechanical properties of the mandible. Defects that were $12 \mathrm{~mm} \times 5 \mathrm{~mm}^{32}, 12 \mathrm{~mm} \times 8 \mathrm{~mm}^{29,35}$, and $15 \mathrm{~mm} \times 10 \mathrm{~mm}^{24,30}$ in size were created and hemi-mandible flexural properties were evaluated. The $12 \mathrm{~mm} \times 5 \mathrm{~mm}$ size allowed the simulation of a physiologically stabilized defect without the need for additional fixation while the larger defect sizes were significantly weaker in terms of flexural strength and modulus. Mechanical stability is one of the crucial elements required for bone regeneration $^{36}$ and if the mandibular bone is compromised due to the creation of the defect, fixation through stainless steel wire $^{27,35}$, plating ${ }^{18,21}$ or usage of bicortical screws ${ }^{16}$ is essential

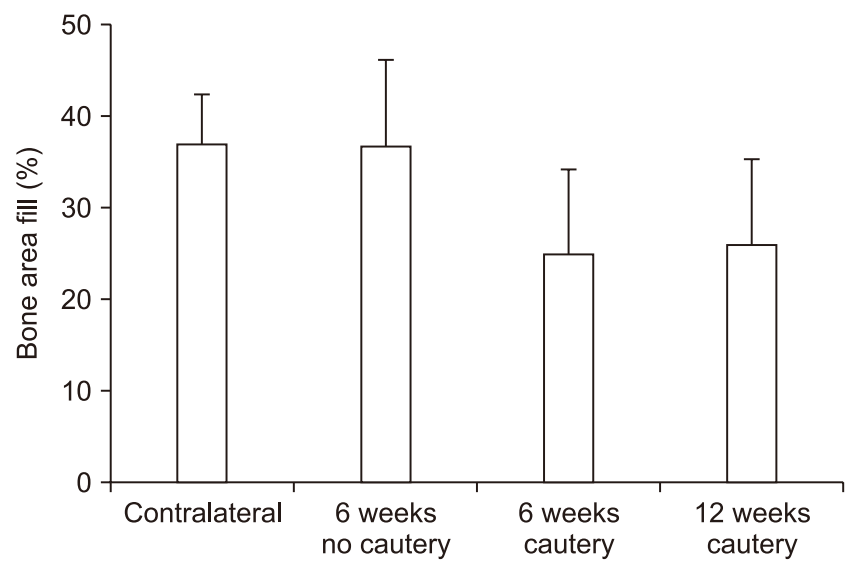

Fig. 6. Histomorphometric analysis of bone area regenerated at the defect site. While no significant differences were observed between the different groups in terms of the area of bone regeneration, a strong trend $(P=0.16)$ of lower mineralized area was observed in the groups with cautery compared to the group without cautery or the contralateral hemi-mandible.

Patricia L. Carlisle et al: Are critical size bone notch defects possible in the rabbit mandible? J Korean Assoc Oral Maxillofac Surg 2019

for rigid fixation. However, rigid fixation of the mandible also leads to potential stress shielding and poor bone regeneration at the defect site. Not plating the mandible can also be seen as a benefit to bone healing as described in a recent study by Zoumalan et al. ${ }^{37}$. They speculated that stresses on the mandible are required for bone formation and that plating of the mandible may act as a stress shield to the healing bone which, in turn, results in insufficient boney healing ${ }^{37}$. The 12 $\mathrm{mm} \times 5 \mathrm{~mm}$ defect size was chosen for further evaluation in this study to reduce the need for mechanical fixation in the model and to easily evaluate novel therapeutics in a large volumetric bone defect. A similar strategy is used in the case of the rabbit radius CSD model for extremity trauma where the presence of the fused ulna provides anatomical internal fixation and stability without the need for further support ${ }^{38}$. An additional advantage of the notch defect site at the inferior margin of the mandibular body is that it avoids damage to muscles of mastication and eliminates the chance of infection from intra-oral flora. Defects with communication to the oral cavity could have potential complications due to excessive soft tissue prolapse and infection ${ }^{21}$.

In the case of notch type defect models in the rabbit model, multiple studies have evaluated defects of various sizes at different locations in the mandible with little consistency, leading to great difficulty in comparing results across these studies $^{24-32,35,39-41}$. In Table 3, these studies are compared in terms of the size and location of the defect, age of the animal, type of fixation if any and methods of evaluation used. In 
Table 3. Variations in defect size and volume in literature reports of critical-sized notch defects in the rabbit mandible

\begin{tabular}{|c|c|c|c|c|c|c|c|c|c|}
\hline & $\begin{array}{l}\text { Size } \\
(\mathrm{mm})\end{array}$ & $\begin{array}{l}\text { Volume } \\
\left(\mathrm{mm}^{3}\right)\end{array}$ & Side & $\begin{array}{l}\text { Weight } \\
(\mathrm{kg})\end{array}$ & $\begin{array}{l}\text { Animal/ } \\
\text { group }\end{array}$ & Fixation & $\begin{array}{l}\text { Evaluation } \\
\text { (wk) }\end{array}$ & Characterization & Defect site \\
\hline $\mathrm{Lu}$ and $\mathrm{Rabie}^{24,40}$ & $15 \times 10$ & 450 & Bilateral & $3.5-4$ & 6 & $\begin{array}{l}\text { Stainless } \\
\text { steel wire }\end{array}$ & 3 & $\begin{array}{l}\text { Micro-CT, } \\
\text { histology }\end{array}$ & $\begin{array}{l}\text { No empty } \\
\text { defect group }\end{array}$ \\
\hline Zhang et al. ${ }^{26}$ & $15 \times 10$ & 450 & Bilateral & 3.5 & 5 & None & $4,12,24$ & $\begin{array}{l}\text { Radiographs, } \\
\text { histomorphometry }\end{array}$ & $\begin{array}{l}\text { Healing } \\
\text { observed }\end{array}$ \\
\hline Guo et al. ${ }^{27}$ & $15 \times 8$ & 360 & Bilateral & 2.5 & 6 & $\begin{array}{l}\text { Stainless } \\
\text { steel wire }\end{array}$ & $2,4,12$ & $\begin{array}{l}\text { Radiographs, } \\
\text { micro-CT, } \\
\text { histology }\end{array}$ & $\begin{array}{r}\text { No healing } \\
\text { observed }\end{array}$ \\
\hline Yoshimoto et al. ${ }^{41}$ & $12 \times 9$ & 324 & Bilateral & 3 & 3 & None & $2,4,8$ & Histomorphometry & $\begin{array}{c}\text { Some healing } \\
\text { observed }\end{array}$ \\
\hline Wang et al. ${ }^{35}$ & $12 \times 8$ & 288 & Unilateral & 3 & 4 & $\begin{array}{l}\text { Stainless } \\
\text { steel wire }\end{array}$ & $2,4,8,12$ & Histomorphometry & $\begin{array}{l}\text { Data } \\
\text { unavailable }\end{array}$ \\
\hline Li et al. ${ }^{29}$ & $12 \times 8$ & 288 & Bilateral & 3 & 6 & None & $4,8,16$ & $\begin{array}{l}\text { Radiographs, } \\
\text { biomechanics, } \\
\text { histomorphometry }\end{array}$ & $\begin{array}{l}\text { No empty } \\
\text { defect group }\end{array}$ \\
\hline Jiang et al. ${ }^{39}$ & $15 \times 6$ & 270 & Bilateral & 2 & 4 & None & 4 & Histomorphometry & $\begin{array}{l}\text { Data } \\
\text { unavailable }\end{array}$ \\
\hline Asikainen et al. ${ }^{31}$ & $12 \times 6$ & 216 & Bilateral & $2.5-3$ & 6 & None & $6,12,24$ & $\begin{array}{l}\text { Radiographs, } \\
\text { histology }\end{array}$ & $\begin{array}{c}\text { No healing } \\
\text { observed }\end{array}$ \\
\hline Zhang et al. ${ }^{30}$ & $10 \times 6$ & 180 & Unilateral & 3 & 1 & $\begin{array}{l}\text { Stainless } \\
\text { steel wire }\end{array}$ & $2,4,8$ & Histology & $\begin{array}{l}\text { No empty } \\
\text { defect group }\end{array}$ \\
\hline Ye et al. ${ }^{28}$ & $10 \times 6$ & 180 & Unilateral & 3 & - & $\begin{array}{l}\text { Stainless } \\
\text { steel wire }\end{array}$ & 4,12 & Histology & $\begin{array}{l}\text { No empty } \\
\text { defect group }\end{array}$ \\
\hline Ren et al. ${ }^{32}$ & $12 \times 5$ & 180 & Unilateral & - & 2 & None & 6,12 & Histomorphometry & $\begin{array}{l}\text { Data } \\
\text { unavailable }\end{array}$ \\
\hline Miloro et al. ${ }^{25}$ & $10 \times 5$ & 150 & Bilateral & - & 2 & None & $4,8,12$ & $\begin{array}{l}\text { Radiographs, } \\
\text { histology }\end{array}$ & $\begin{array}{l}\text { Healing } \\
\text { observed }\end{array}$ \\
\hline This study & $12 \times 5$ & 180 & Unilateral & $4-5$ & 6 & None & 6,12 & $\begin{array}{l}\text { Radiography, } \\
\text { micro-CT, } \\
\text { histomorphometry }\end{array}$ & $\begin{array}{l}\text { Healing } \\
\text { observed }\end{array}$ \\
\hline
\end{tabular}

(CT: computed tomography, -: not provide)

The evaluation techniques, number of animals evaluated in each experimental group, use of fixators for stabilization, duration of evaluation and the nature of regeneration observed in untreated defect sites are inconsistent across the various studies.

Patricia L. Carlisle et al: Are critical size bone notch defects possible in the rabbit mandible? J Korean Assoc Oral Maxillofac Surg 2019

comparison, skeletally mature rabbits weighing between $4-5$ $\mathrm{kg}$ and greater than 21 weeks of age ${ }^{42}$ were used for unilateral defect creation in the current study. The evaluation of bone regeneration at the defect site indicated that significant bone regeneration occurred over 6 weeks in the $180 \mathrm{~mm}^{3}$ defect when the defect margins were not cauterized and over 12 weeks when the defect margins were cauterized. Thus, contrary to other reports of $180 \mathrm{~mm}^{3}$ defects being considered $\operatorname{CSDs}^{28,30,32}$ we observed that this defect size did not meet the requisite criteria to be used as a CSD in the rabbit mandible.

Previous studies also state that the location within the mandible is of critical importance in determining the extent of bone regeneration at the defect site. Guo et al. ${ }^{27}$ demonstrated that the presence of greater marrow adjacent to the defect leads to a more robust regenerative response possibly because of a greater number of stem cells. Similarly, in our study, we observed a robust regenerative response from the base of the teeth roots, where the defect had been created. Histological evidence of periodontal like tissue was also observed in the group without cautery of the defect margin. Although not directly investigated in this study, it is possible that the periodontal ligament and mandibular bone marrow stem cells could have played a role in the robust regenerative response at the defect site. The bone regenerative capacity of periodontal ligament and bone marrow stem cells has been previously reported in other in vivo models ${ }^{43,44}$.

Cauterization of the bone defect margins as a technique to inhibit regeneration and create non-union models has been previously employed in rat femoral defects ${ }^{45,46}$. Since the $12 \mathrm{~mm} \times 5 \mathrm{~mm}$ defect created in the present study healed spontaneously over 6 weeks, cautery of the defect margins was employed in order to make the defect model more challenging. However, even after inhibition of bone growth by cauterization, the regenerated bone increased from 6 to 12 weeks reaching a level similar to the non-cauterized bone at 6 weeks. Cauterization of the defect margins did; however, result in a delay of the bone growth and demonstrably increased tissue debris at the defect margins. The presence of tissue debris and decreased regeneration at the defect site suggests that the cauterization limited the vascular infiltration from the 
bony margins and delayed the recruitment of stem cell populations to the defect site. It should be noted that only electrocautery was tested in this study and not the effect on the local responsive cell population if a different form of inhibition (such as chemical cauterization $^{47}$ ) were to be employed.

Bone growing into the exposed root canals may be a further indicator of an aggressive osteogenic response from periodontal and dental stem cells due to the alteration in the local microenvironment as a result of creating a non-segmental defect without tooth extraction. Traumatic injuries to immature teeth have been reported to result in the in-growth of mineralized tissues within the dental canal and pulp chamber $^{48,49}$. Wang et al. ${ }^{50}$ described multiple histologic responses, including intercanal bone in immature canine teeth following the use of antibiotic paste, suggesting a possible relationship between inflammatory responses and canal mineralization.

While several groups have previously reported the performance of bone regenerative therapies in the rabbit mandible, many have chosen to not include an empty defect group ${ }^{28,29,40}$ or have poorly described the regenerative outcomes of such a group ${ }^{32,39}$. Given the spontaneous regeneration of the defect site observed in this study and reported by others for mandibular defects in rabbits ${ }^{19}$, it is recommended that future studies comprehensively characterize the chosen defect model, resort to well-characterized CSDs in the rabbit calvaria, or choose larger animal models to evaluate regenerative efficacy at mandibular sites.

\section{Conclusion}

Contrary to multiple literature reports that have used the full thickness notch defect model in the rabbit mandible to evaluate regenerative therapies, this study showed that a 12 $\mathrm{mm} \times 5 \mathrm{~mm}$ defect is biomechanically stable and cannot be considered critical-sized even with cauterization. Since cauterization was found to delay healing by 6 weeks, a potential application of this model could be to evaluate bone regenerative therapeutics that accelerate bone re-growth rather than simply the success or failure of therapy.

\section{ORCID}

Patricia L. Carlisle, https://orcid.org/0000-0001-6781-017X

Teja Guda, https://orcid.org/0000-0002-3218-2916

David T. Silliman, https://orcid.org/0000-0001-6440-4694

Robert G. Hale, https://orcid.org/0000-0002-9699-3224

Pamela R. Brown Baer, https://orcid.org/0000-0001-6964-1955

\section{Authors' Contributions}

P.R.B.B., R.G.H., and D.T.S. contributed to the conception and design of the study; P.R.B.B., D.T.S., and T.G. contributed to the acquisition of data and P.L.C., P.R.B.B., D.T.S., and T.G. contributed to the analysis and interpretation of data. All authors contributed to drafting and revising the article and provided the final approval of the version submitted.

\section{Acknowledgements}

This study was supported by the Department of Defense and Grant \#G_021_2010 at the United States Army Institute of Surgical Research. No other conflicts of interest are present or perceived.

The authors would like to acknowledge Mr. James Herrick (Mayo Clinic) for his assistance with the histological analysis.

The opinions or assertions contained herein are the private views of the authors and are not to be construed as official or as reflecting the views of the Department of the Army or the Department of Defense.

\section{Ethics Approval and Consent to Participate}

This study has been conducted in compliance with the Animal Welfare Act, implementing Animal Welfare Regulations, and the principles of the Guide for the Care and Use of Laboratory Animals.

\section{Conflict of Interest}

No potential conflict of interest relevant to this article was reported.

\section{References}

1. Glendor U. Aetiology and risk factors related to traumatic dental injuries--a review of the literature. Dent Traumatol 2009;25:19-31.

2. Zachar MR, Labella C, Kittle CP, Baer PB, Hale RG, Chan RK. Characterization of mandibular fractures incurred from battle injuries in Iraq and Afghanistan from 2001-2010. J Oral Maxillofac Surg 2013;71:734-42.

3. Schmitz JP, Hollinger JO. The critical size defect as an experimental model for craniomandibulofacial nonunions. Clin Orthop Relat Res 1986;(205):299-308.

4. Cooper GM, Mooney MP, Gosain AK, Campbell PG, Losee JE, Huard J. Testing the critical size in calvarial bone defects: revisiting the concept of a critical-size defect. Plast Reconstr Surg 2010;125:1685-92.

5. Vajgel A, Mardas N, Farias BC, Petrie A, Cimões R, Donos N. A systematic review on the critical size defect model. Clin Oral Implants Res 2014;25:879-93. 
6. Guda T, Darr A, Silliman DT, Magno MH, Wenke JC, Kohn J, et al. Methods to analyze bone regenerative response to different rhBMP-2 doses in rabbit craniofacial defects. Tissue Eng Part C Methods 2014;20:749-60.

7. Dumas JE, BrownBaer PB, Prieto EM, Guda T, Hale RG, Wenke $\mathrm{JC}$, et al. Injectable reactive biocomposites for bone healing in critical-size rabbit calvarial defects. Biomed Mater 2012;7:024112.

8. Choi BH, Im CJ, Huh JY, Suh JJ, Lee SH. Effect of platelet-rich plasma on bone regeneration in autogenous bone graft. Int J Oral Maxillofac Surg 2004;33:56-9.

9. Carlisle PL, Guda T, Silliman DT, Lien W, Hale RG, Brown Baer PR. Investigation of a pre-clinical mandibular bone notch defect model in miniature pigs: clinical computed tomography, microcomputed tomography, and histological evaluation. J Korean Assoc Oral Maxillofac Surg 2016;42:20-30.

10. Carstens MH, Chin M, Li XJ. In situ osteogenesis: regeneration of $10-\mathrm{cm}$ mandibular defect in porcine model using recombinant human bone morphogenetic protein-2 (rhBMP-2) and Helistat absorbable collagen sponge. J Craniofac Surg 2005;16:1033-42.

11. Herford AS, Boyne PJ. Reconstruction of mandibular continuity defects with bone morphogenetic protein-2 (rhBMP-2). J Oral Maxillofac Surg 2008;66:616-24.

12. Chim H, Gosain AK. Biomaterials in craniofacial surgery: experimental studies and clinical application. J Craniofac Surg 2009;20:29-33.

13. Misch CE, Qu Z, Bidez MW. Mechanical properties of trabecular bone in the human mandible: implications for dental implant treatment planning and surgical placement. J Oral Maxillofac Surg 1999;57:700-6; discussion 706-8.

14. Hollinger JO, Kleinschmidt JC. The critical size defect as an experimental model to test bone repair materials. J Craniofac Surg 1990;1:60-8.

15. Zwetyenga N, Catros S, Emparanza A, Deminiere C, Siberchicot F, Fricain JC. Mandibular reconstruction using induced membranes with autologous cancellous bone graft and HA-betaTCP: animal model study and preliminary results in patients. Int J Oral Maxillofac Surg 2009;38:1289-97.

16. Busuttil Naudi K, Ayoub A, McMahon J, Di Silvio L, Lappin D, Hunter KD, et al. Mandibular reconstruction in the rabbit using beta-tricalcium phosphate ( $\beta$-TCP) scaffolding and recombinant bone morphogenetic protein 7 (rhBMP-7): histological, radiographic and mechanical evaluations. J Craniomaxillofac Surg 2012;40:e461-9.

17. Liu HY, Liu X, Zhang LP, Ai HJ, Cui FZ. Improvement on the performance of bone regeneration of calcium sulfate hemihydrate by adding mineralized collagen. Tissue Eng Part A 2010;16:2075-84.

18. Young S, Bashoura AG, Borden T, Baggett LS, Jansen JA, Wong M, et al. Development and characterization of a rabbit alveolar bone nonhealing defect model. J Biomed Mater Res A 2008;86:182-94.

19. Eleftheriadis E, Leventis MD, Tosios KI, Faratzis G, Titsinidis S, Eleftheriadi I, et al. Osteogenic activity of $\beta$-tricalcium phosphate in a hydroxyl sulphate matrix and demineralized bone matrix: a histological study in rabbit mandible. J Oral Sci 2010;52:377-84.

20. Kim KN, Yang JE, Jang JW, Sasikala B, Beng W, Kim IK. Morphometric analysis on bone formation effect of $\beta$-TCP and rhBMP-2 in rabbit mandible. J Korean Assoc Oral Maxillofac Surg 2010;36:161-71.

21. Nguyen C, Young S, Kretlow JD, Mikos AG, Wong M. Surface characteristics of biomaterials used for space maintenance in a mandibular defect: a pilot animal study. J Oral Maxillofac Surg 2011;69:11-8.

22. He H, Yan W, Chen G, Lu Z. Acceleration of de novo bone formation with a novel bioabsorbable film: a histomorphometric study in vivo. J Oral Pathol Med 2008;37:378-82.

23. Shah SR, Young S, Goldman JL, Jansen JA, Wong ME, Mikos AG. A composite critical-size rabbit mandibular defect for evaluation of craniofacial tissue regeneration. Nat Protoc 2016;11:1989-2009.

24. Lu M, Rabie AB. Microarchitecture of rabbit mandibular defects grafted with intramembranous or endochondral bone shown by micro-computed tomography. Br J Oral Maxillofac Surg 2003;41:38591.

25. Miloro M, Haralson DJ, Desa V. Bone healing in a rabbit mandibular defect using platelet-rich plasma. J Oral Maxillofac Surg 2010;68:1225-30.

26. Zhang JC, Lu HY, Lv GY, Mo AC, Yan YG, Huang C. The repair of critical-size defects with porous hydroxyapatite/polyamide nanocomposite: an experimental study in rabbit mandibles. Int $\mathrm{J}$ Oral Maxillofac Surg 2010;39:469-77.

27. Guo J, Meng Z, Chen G, Xie D, Chen Y, Wang H, et al. Restoration of critical-size defects in the rabbit mandible using porous nanohydroxyapatite-polyamide scaffolds. Tissue Eng Part A 2012;18:1239-52.

28. Ye L, Zeng X, Li H, Wang Z. Fabrication and biocompatibility of porously bioactive scaffold of nonstoichiometric apatite and poly $(\varepsilon-$ caprolactone) nanocomposite. J Appl Polym Sci 2010;116:762-70.

29. Li J, Li Y, Ma S, Gao Y, Zuo Y, Hu J. Enhancement of bone formation by BMP-7 transduced MSCs on biomimetic nano-hydroxyapatite/polyamide composite scaffolds in repair of mandibular defects. J Biomed Mater Res A 2010;95:973-81.

30. Zhang H, Ye XJ, Li JS. Preparation and biocompatibility evaluation of apatite/wollastonite-derived porous bioactive glass ceramic scaffolds. Biomed Mater 2009;4:045007.

31. Asikainen AJ, Noponen J, Lindqvist C, Pelto M, Kellomäki M, Juuti $\mathrm{H}$, et al. Tyrosine-derived polycarbonate membrane in treating mandibular bone defects. An experimental study. J R Soc Interface 2006;3:629-35.

32. Ren J, Ren T, Zhao P, Huang Y, Pan K. Repair of mandibular defects using MSCs-seeded biodegradable polyester porous scaffolds. J Biomater Sci Polym Ed 2007;18:505-17.

33. Bulut T, Durmuş E, Mihmanlı A, Dolanmaz D, Kalaycı A, Sağlam H. Distracted mandible does not reach the same strength as normal mandible in rabbits. Oral Surg Oral Med Oral Pathol Oral Radiol 2012;114(5 Suppl):S140-5.

34. Erdogan O, Esen E, Ustün Y, Kürkçü M, Akova T, Gönlüşen G, et al. Effects of low-intensity pulsed ultrasound on healing of mandibular fractures: an experimental study in rabbits. J Oral Maxillofac Surg 2006;64:180-8.

35. Wang H, Li Y, Zuo Y, Li J, Ma S, Cheng L. Biocompatibility and osteogenesis of biomimetic nano-hydroxyapatite/polyamide composite scaffolds for bone tissue engineering. Biomaterials 2007;28:3338-48.

36. Meyer U, Joos U, Wiesmann HP. Biological and biophysical principles in extracorporal bone tissue engineering. Part III. Int J Oral Maxillofac Surg 2004;33:635-41.

37. Zoumalan RA, Hirsch DL, Levine JP, Saadeh PB. Plating in microvascular reconstruction of the mandible: can fixation be too rigid? J Craniofac Surg 2009;20:1451-4.

38. Guda T, Walker JA, Singleton BM, Hernandez JW, Son JS, Kim $\mathrm{SG}$, et al. Guided bone regeneration in long-bone defects with a structural hydroxyapatite graft and collagen membrane. Tissue Eng Part A 2013;19:1879-88.

39. Jiang X, Gittens SA, Chang Q, Zhang X, Chen C, Zhang Z. The use of tissue-engineered bone with human bone morphogenetic protein-4-modified bone-marrow stromal cells in repairing mandibular defects in rabbits. Int J Oral Maxillofac Surg 2006;35:11339.

40. Lu M, Rabie AB. The effect of demineralized intramembranous bone matrix and basic fibroblast growth factor on the healing of allogeneic intramembranous bone grafts in the rabbit. Arch Oral Biol 2002;47:831-41.

41. Yoshimoto R, Murata M, Akazawa T, Arisue M. Effects of functionally graded hydroxyapatite for large mandibular defects in adult rabbits. J Hard Tissue Biol 2010;19:33-42.

42. Hassanein AH, Couto RA, Nedder A, Zielins ER, Greene AK. Critical-size defect ossification: effect of leporid age in a cranioplasty 
model. J Craniofac Surg 2011;22:2341-3.

43. Huang GT, Gronthos S, Shi S. Mesenchymal stem cells derived from dental tissues vs. those from other sources: their biology and role in regenerative medicine. J Dent Res 2009;88:792-806.

44. Kim SH, Kim KH, Seo BM, Koo KT, Kim TI, Seol YJ, et al. Alveolar bone regeneration by transplantation of periodontal ligament stem cells and bone marrow stem cells in a canine peri-implant defect model: a pilot study. J Periodontol 2009;80:1815-23.

45. Kokubu T, Hak DJ, Hazelwood SJ, Reddi AH. Development of an atrophic nonunion model and comparison to a closed healing fracture in rat femur. J Orthop Res 2003;21:503-10.

46. Mills LA, Simpson AH. In vivo models of bone repair. J Bone Joint Surg Br 2012;94:865-74.
47. Regan JD, Witherspoon DE, Foyle D. Surgical repair of root and tooth perforations. Endodontic Topics 2005;11:152-78.

48. Andreasen JO, Borum MK, Andreasen FM. Replantation of 400 avulsed permanent incisors. 3. Factors related to root growth. Endod Dent Traumatol 1995;11:69-75.

49. Robertson A. A retrospective evaluation of patients with uncomplicated crown fractures and luxation injuries. Endod Dent Traumatol 1998;14:245-56.

50. Wang X, Thibodeau B, Trope M, Lin LM, Huang GT. Histologic characterization of regenerated tissues in canal space after the revitalization/revascularization procedure of immature dog teeth with apical periodontitis. J Endod 2010;36:56-63. 